Per manent magnet bear i ngs for hor i zont al - and vert i cal-shaft machi nes: A compar at i ve st udy

\begin{tabular}{|l|l|}
\hline 著者 & $\begin{array}{l}\text { Ohj i Takahi sa, Mkhopadhyay S. C. , I wahar a } \\
\text { Nasay oshi, Yamada Sot oshi }\end{array}$ \\
\hline $\begin{array}{l}\text { j our nal or } \\
\text { publ i cat i on ti t l e }\end{array}$ & Jour nal of Appl i ed Physi cs \\
\hline vol une & 85 \\
\hline number & 8 II-A \\
\hline page r ange & $4648-4650$ \\
\hline year & $1999-04$ 15 \\
\hline URL & ht t p: //hdl . handl e. net /2297/48635 \\
\hline
\end{tabular}




\title{
Permanent magnet bearings for horizontal- and vertical-shaft machines: A comparative study
}

\author{
T. Ohji, S. C. Mukhopadhyay, ${ }^{a)} \mathrm{M}$. Iwahara, and S. Yamada \\ Faculy of Enginering. Kanazawa University, Kodatsmo 2-40.20, Kanazawa 920, Japan
}

Two types of magnclic bearing systems employing permanent magnets to be used for vertical-shaft and horizontal-shaft machines, respectively, have been designed and fabricated in our laboratory. In this article we report a comparative cvaluation of (i) the permanent magnet configuration and its effect on radial disturbance allenuation, (ii) magnetic losses and their effect on energy storage, and (iii) the orf-state position of the rotor magnet in two types of bearing systems. Experimental results are presenled. (c) 1999 American Lnstinuc of Physics. [S0021-8979(99)55708-3]

\section{INTRODUCTION}

Active magnelic bearing systcms, becausc of their adjustable damping and stiffness characteristics, have many applications in industry workfwide. Permanent magnet benting systems do not need many electromagnets so they have a

mplified control schene. The structural design, axis of magnetization, calculation of forces, and stiffnesses of different lypes of permanent magnet bearing arrangements for vertical-shaft machine conftguralion have been described in Rer. 2. However, many magnetic bearing applications require horizontal operation. Little information regarding the design and control of permanent magnel configurations for horizontal-shaft type magnetic hearing systems has becn reported in the filerature.

In this anticle we discuss a few aspects such as the configuration of permanent magnels, adiat disturbance altemution, magnetic losscs, and the off-state position of a rotor magnet in two repulsive type magnelic bearing systems that arc cmployed in vertical-shaft and horizontai-shaft maclines, respectively.

\section{CONFIGURATION OF PERMANENT MAGNETS AND BEARING SYSTEMS}

The bearing system developed for the vertical-sthaft machine configuration is shown in rig. 1. The permanent magncl (PM) used for this system is shown in Fig. 2. A circular permanent magnet with either axial or radial magnetization is the only choice for this type of bearing system, making it radially stable. Axially magnetized magnels have been used in the model. The circular permanent magnet used for the vertical-shaft machine, if used for the horizontal configura(ion, will result in zero levitation force in the central position atong the radial (i.e., vertical) direction." So the permanent magnet configuration needs some special attention. Since the radial axis is the noncontrolled passive axis, to reduce the effect of radial disturbance higher radial stiffness is desirable. In order to achieve better radial stiffness, a section of the permanent magnet is placed on the upper section of the stator. Placement of the upper stator permanent magnet witt reduce the levitation force, so the are icngth should be selected carefully. A finite element analysis was performed to

"Ficeltonic mail: scmukloparliyay (a) hommail.com achieve a trade-orf between the levitation force and the radial stiffness. ${ }^{4}$ The most desirable permanent magnel configuration is shown in Fig. 3 and the magnetic bearing configuration for the horizontal-shaft machine is shown in Fig. 4.

The principal parameters for the vertical-shaft system are the mass of the rotor $=5.5 \mathrm{~kg}$, the length of the rotor $=420$ $\mathrm{mm}$, and the diameter of the rotor $=200 \mathrm{~mm}$; those for the horizontal-shaft system are $8 \mathrm{~kg}, 510 \mathrm{~mm}$, and $220 \mathrm{~mm}$, respectively.

\section{RADIAL DISTURBANCE ATTENUATION CHARACTERISTICS}

Our aim was to develop a magnetic bearing system will simplified control. Both the systems are unstable along the longitudinal direction. With the help of controlled current electromagnets stability was achieved. The presence of a controlfer helps to obtain desirable characteristics atong this axis. Our interest lies in the noncontrolled raidal axis. To verify whether the system could operate satisfactorily in the presence of a small radial disturbance, the disturbance characteristics were studied by applying a disturbing force along the radial direction. Figure 5 shows the disturbance characteristic along the radial direction for the vertical-shaft machine. It is seen that the system does not loose stability and reaches steady state after some time.

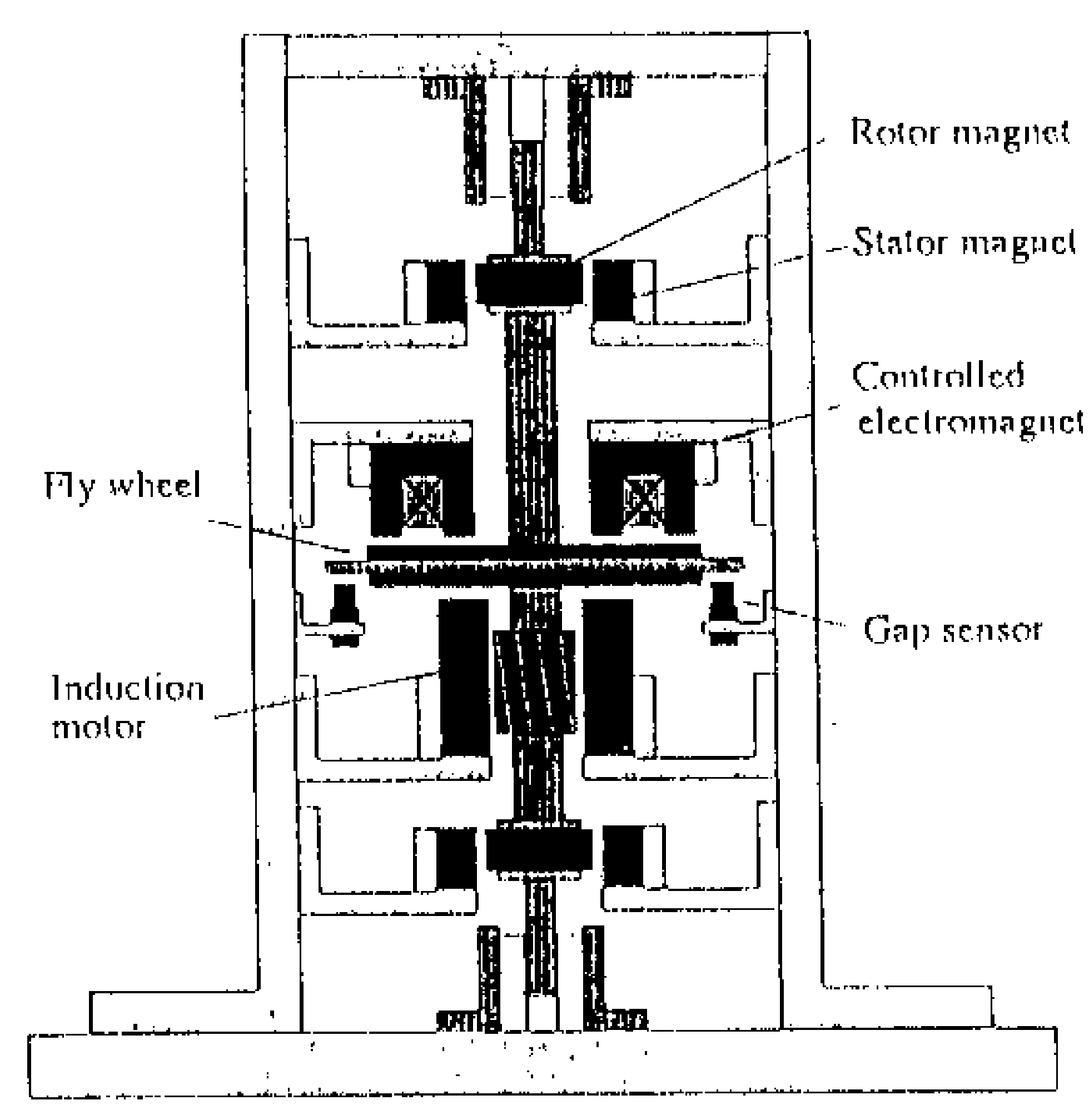

FIG. 1. Configuralion of the vertical-shaft machine. 


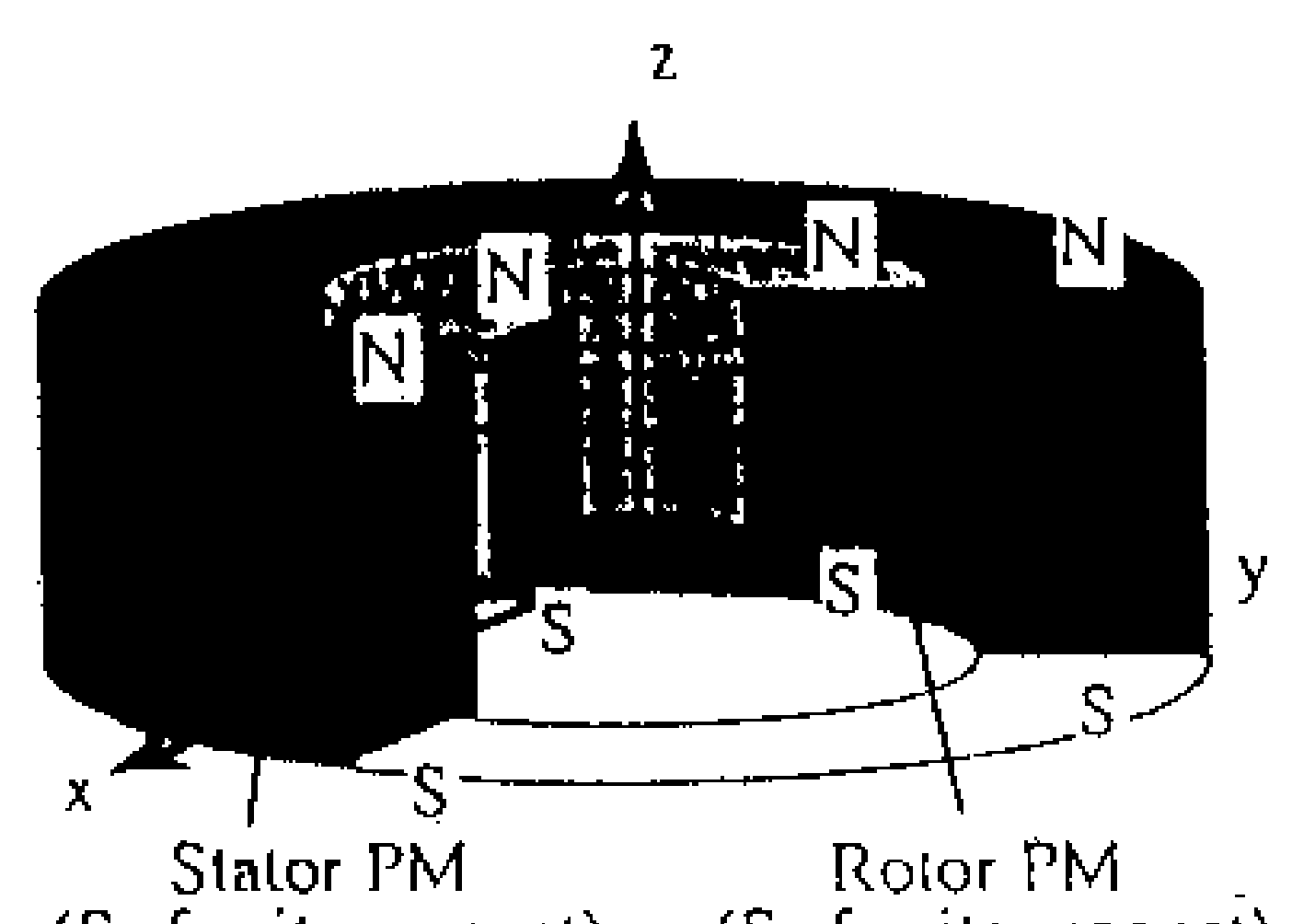

(Sr-ferrite magnel) (Sr-ferite magne)

FIG. 2. Permanent magnel configuration (vertical shaft)

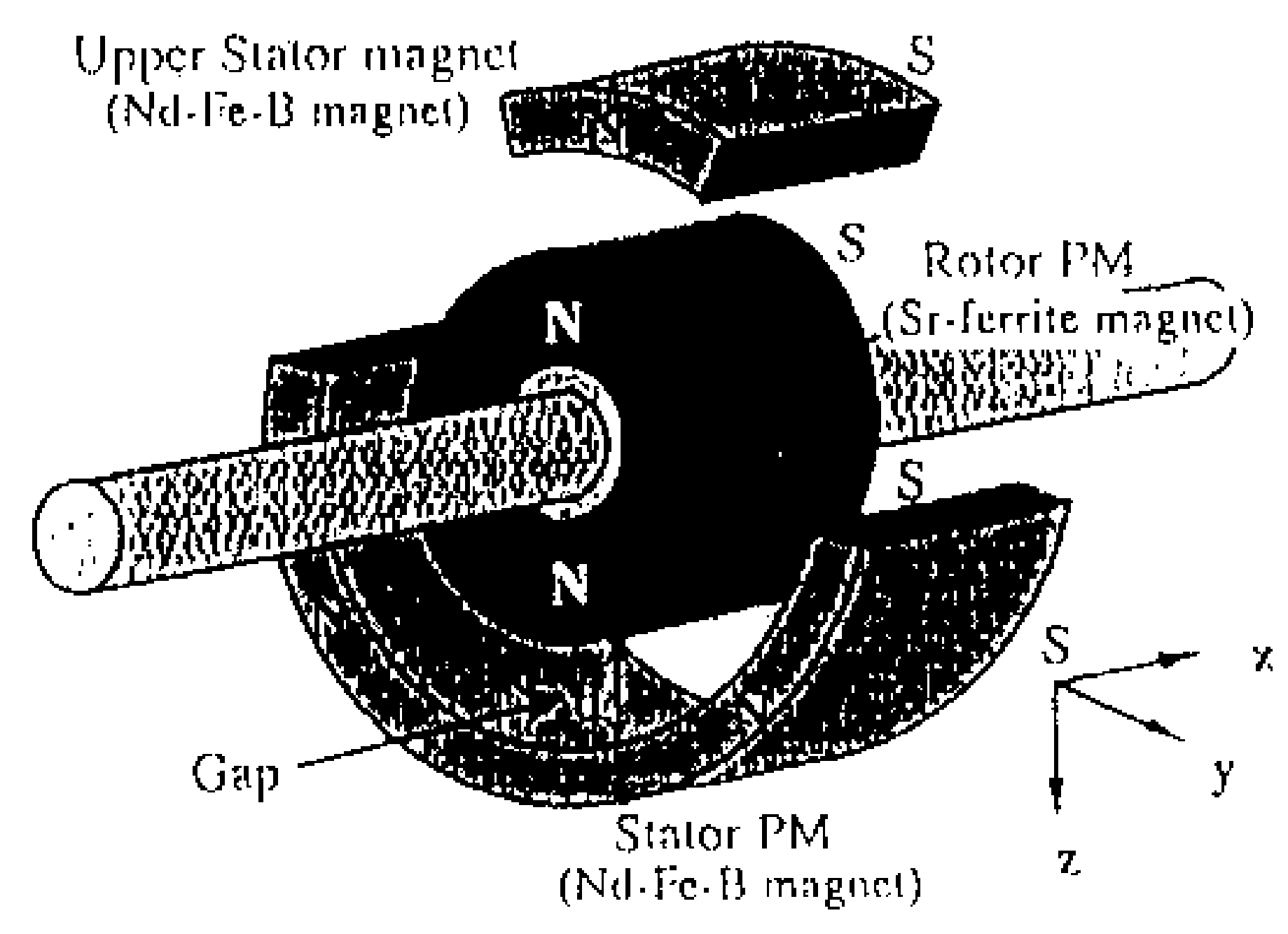

FiG. 3. Permanem magnel configuration (horizontal shaft).

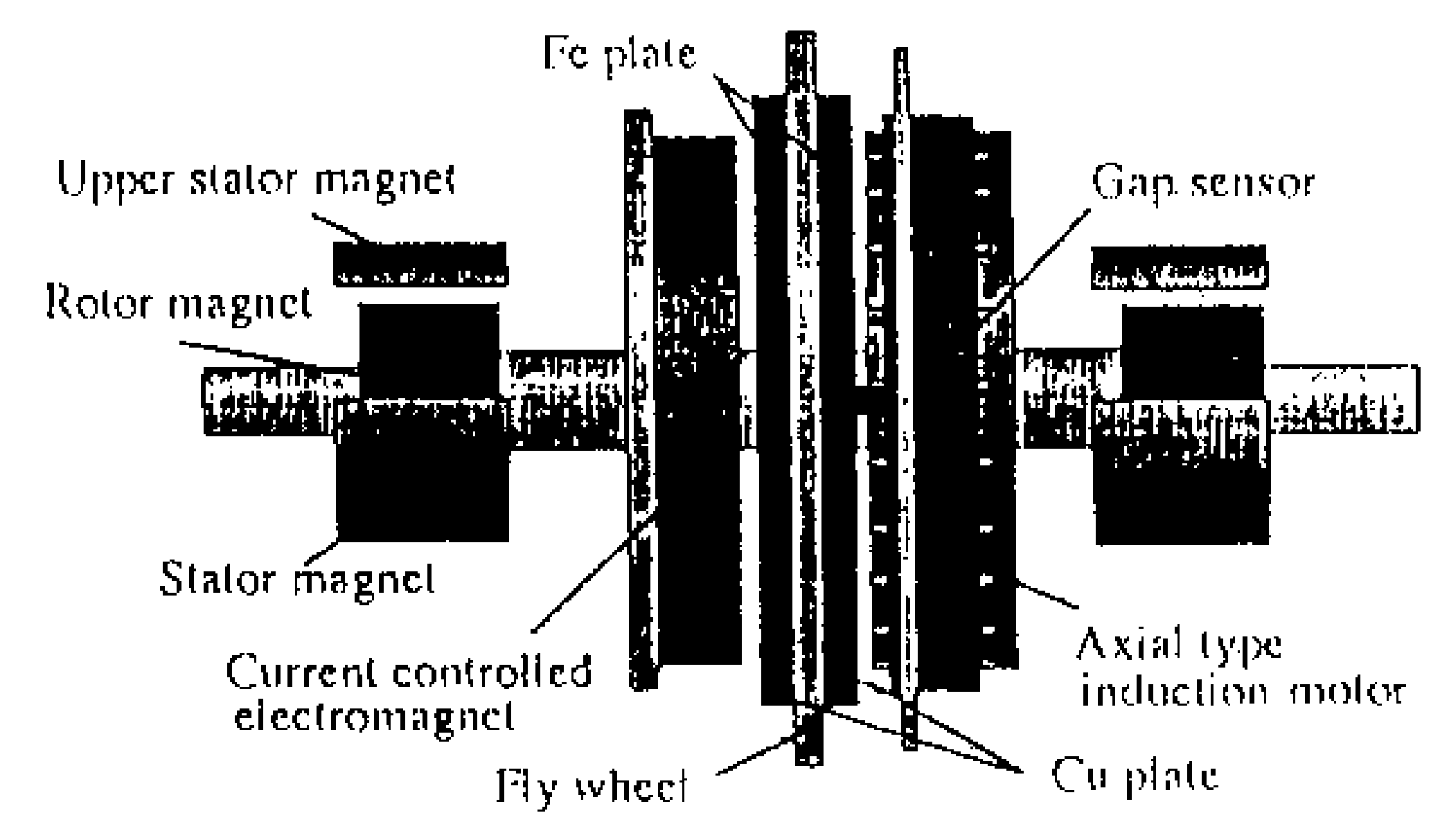

FIG. 4. Configuration of the horizontal-shafl machine.

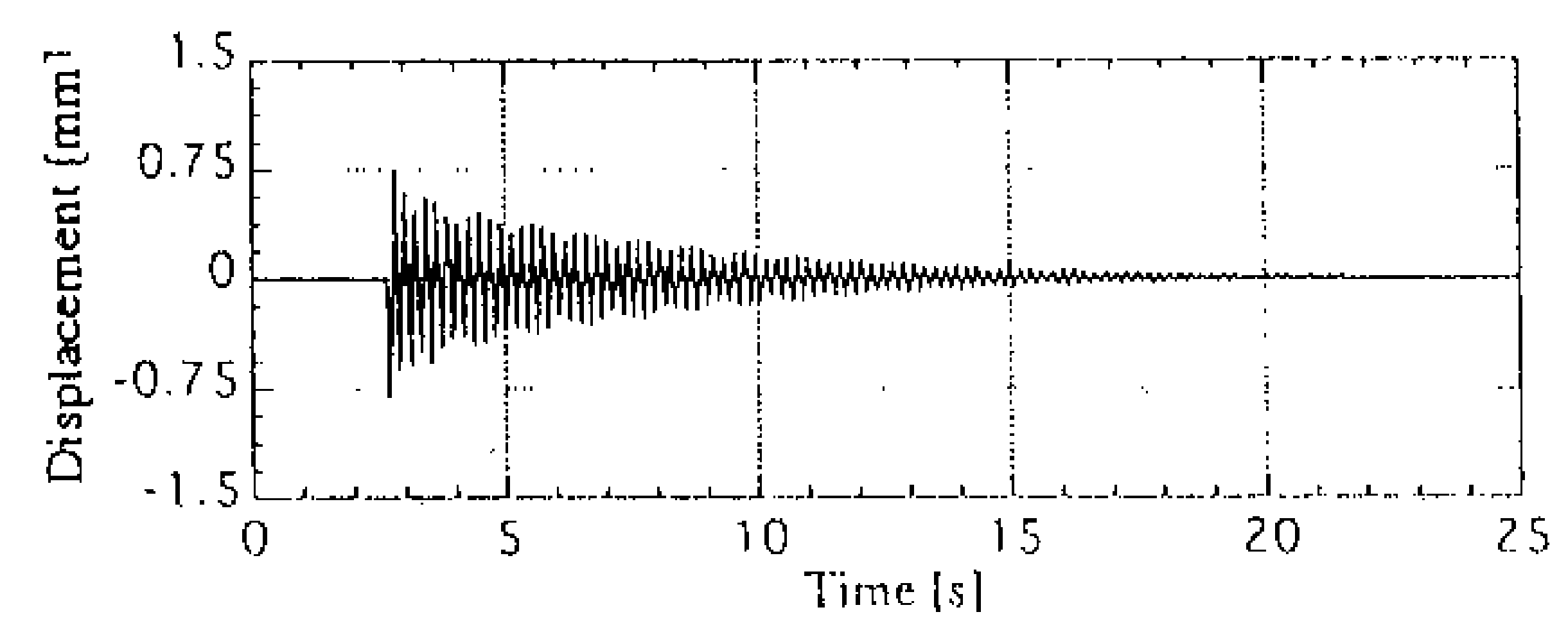

FIG. S. Disturbance characicistics of the verticat system.

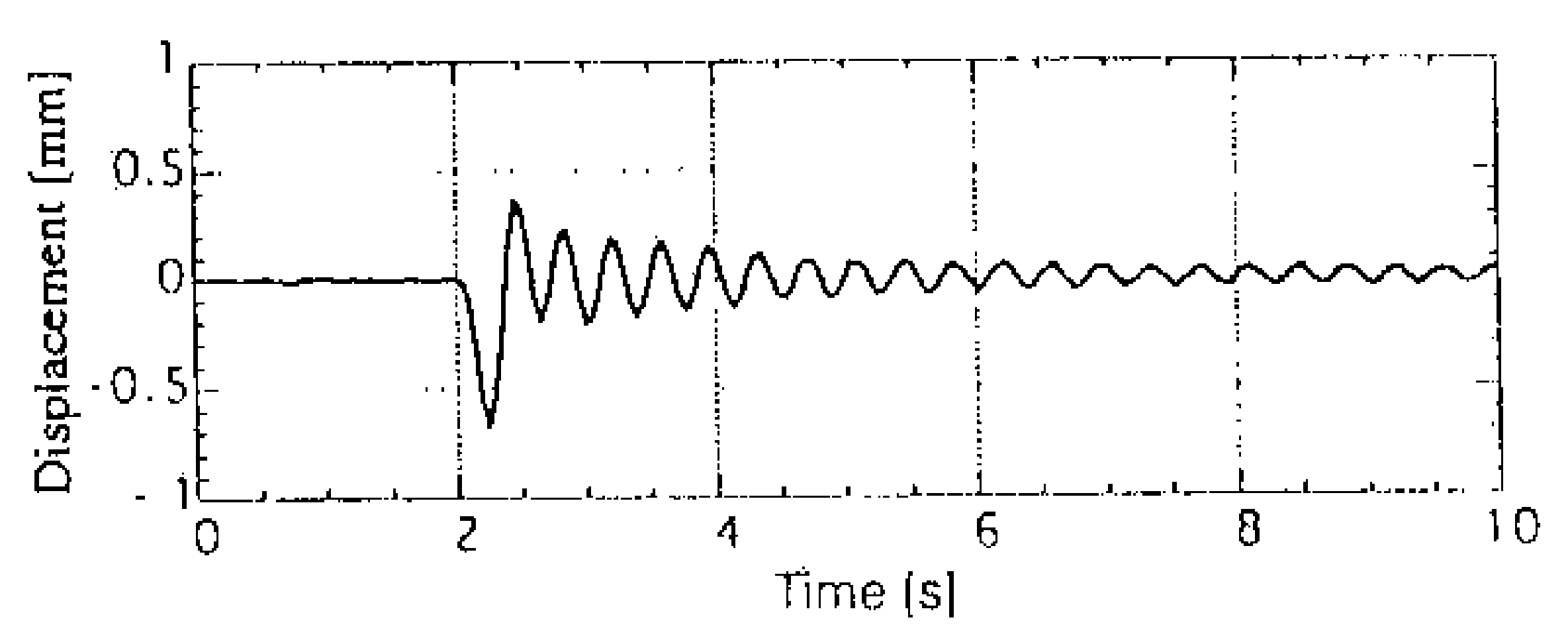

FIG. 6 Disturbance characteristics of the horizontal system without an upper mingel.

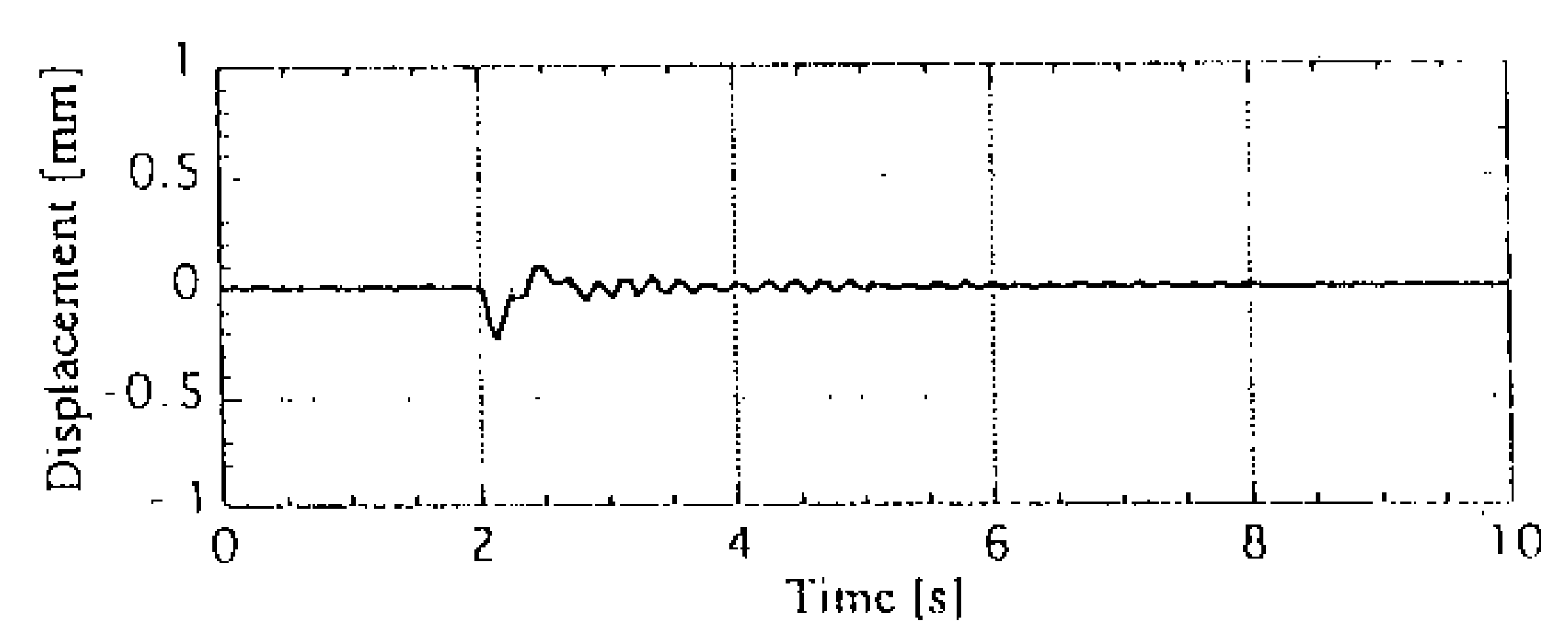

FiG, 7. Disturbance chancletistics of the horizontat system with an upper magned

The radial disturbance characleristics with and without an upper stator magnet section were studied for the horizontal-shaft machine. Figures 6 and 7 show the disturbance characteristics withoul and with an upper stator magnet system, respectively, for the same amount of disturbing force along the radial ditection. It is seen that the presence of an upper stator magnet has reduced the effect of the disturbance and this is due to the improved radial stiffness characieristics. With the horizontal axis adequately controlled the clesired response can be allained.

\section{FIELD DISTRIBUTION AND MAGNETIC LOSSES}

The fietd distribution of the stator and the rotor permanent magnet system of the vertical-shaft and horizonlal-shaft systems is not identical due to their different magnet configurations and consequently they have some effect on the magnetic losses. The field distribution has been measured with the help of gauss meter and Figs. 8 and 9 show the fux-density distribution of the vertical-shaft and horizontalshaft machines, respectively, $1 \mathrm{~mm}$ from the stator inner surface. It is scen that the horizontal-shaft machine has a nonuniform flux distribution. Using the above ficld distribution the manetic losses are calculated as a function of rotor specd with the help of the finite element method. ${ }^{4}$ The loss mainly takes place in the rotor magnet. Figure 10 shows the variation of the magnetic losses with speed for the two types of magnetic bearing syslems. For the vertical-shalt machine the magnetic loss is negligible whereas the horizontal-shaft machine has an appreciable amount of magnetic loss.

\section{DECELERATION CHARACTERISTICS}

If the magnetic bearing is used for the flywheel cnergy storage system, the deceleration characteristics are very important. In the prototype bobratory models, supply frequency nomal induction motors are used so that the specd of operation is not high. Figure 11 shows the deceleration characteristic of the vertical-shaft machine. Since the sizes of the above two bearing systems are not identical, a direct comparison is not possible. But, based on the magnetic loss and total loss, a cleceleration characteristic of the horizontal-shaft machine may be drawn and it is also shown in Fig. 11. Due to the presence of magnelic losses in the horizontal-shalt machine, the reduction of spect is faster and consequently the energy utilization will be less. 


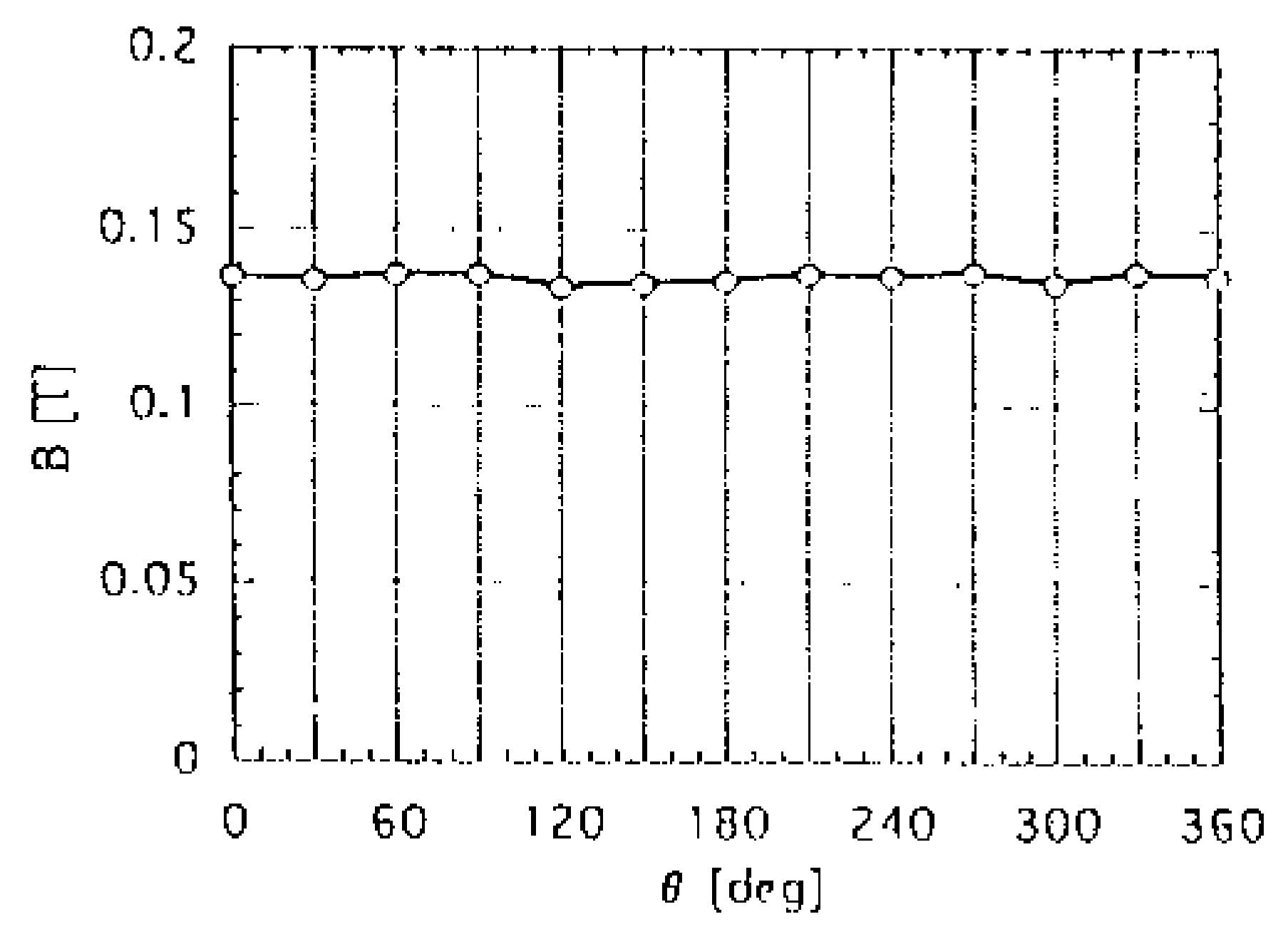

FIG. 8. B-O dingran for the vertical sysicm.

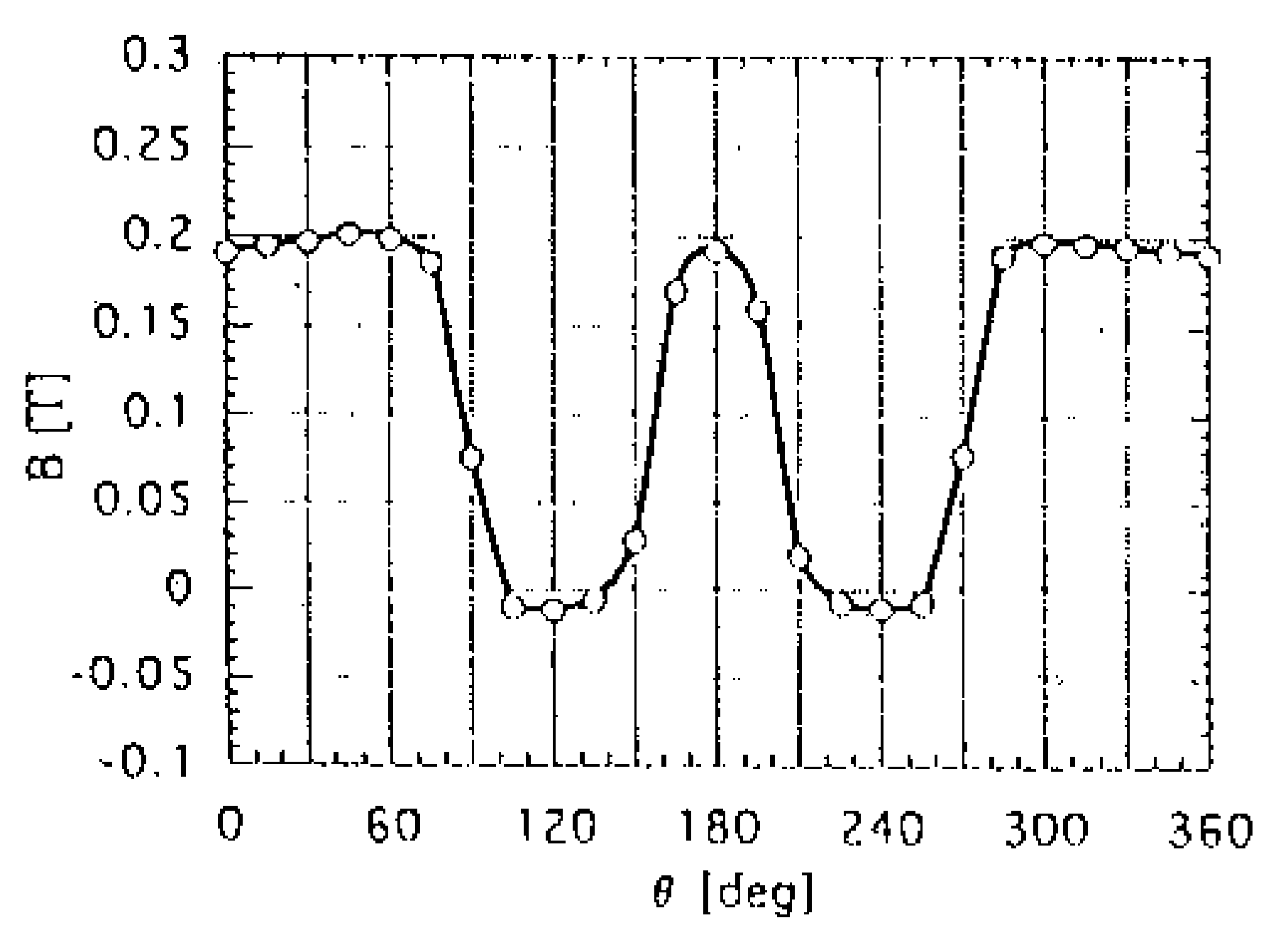

FiG. 9. B-A diagram for the hotizonlal system.

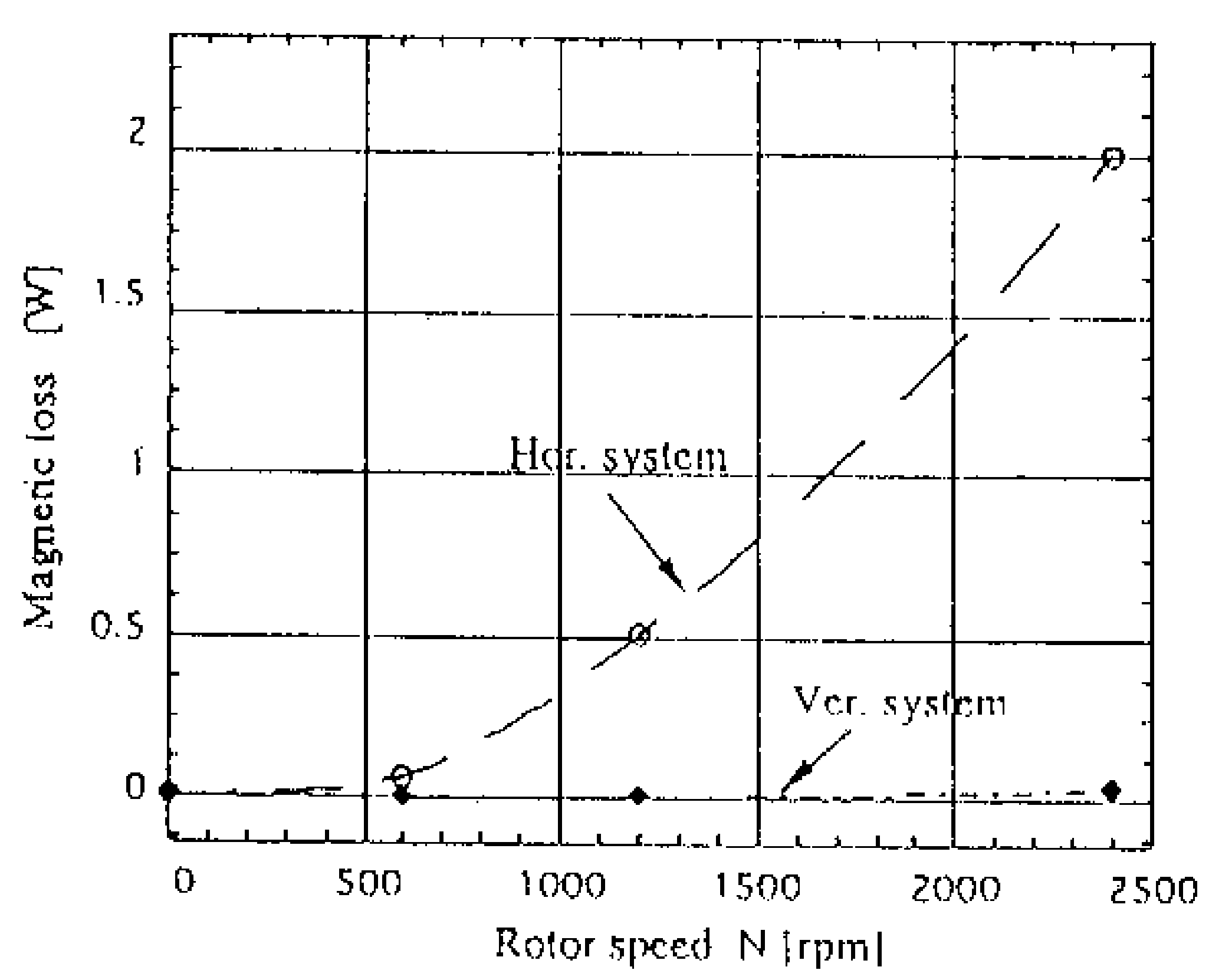

FG. 10. Loss curves for vertical and horizontat systems

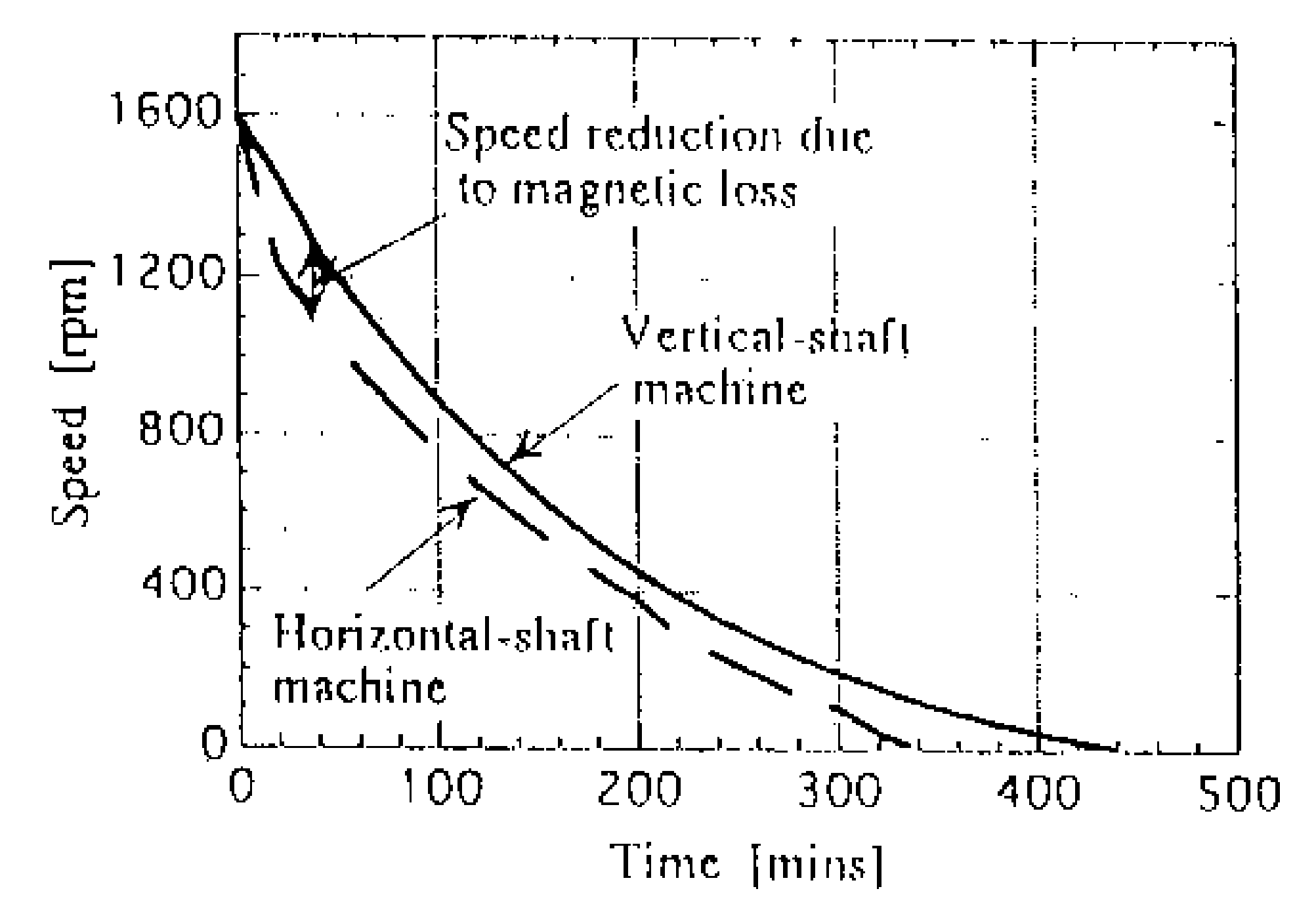

FIG. II. Deceleralion characteristics.

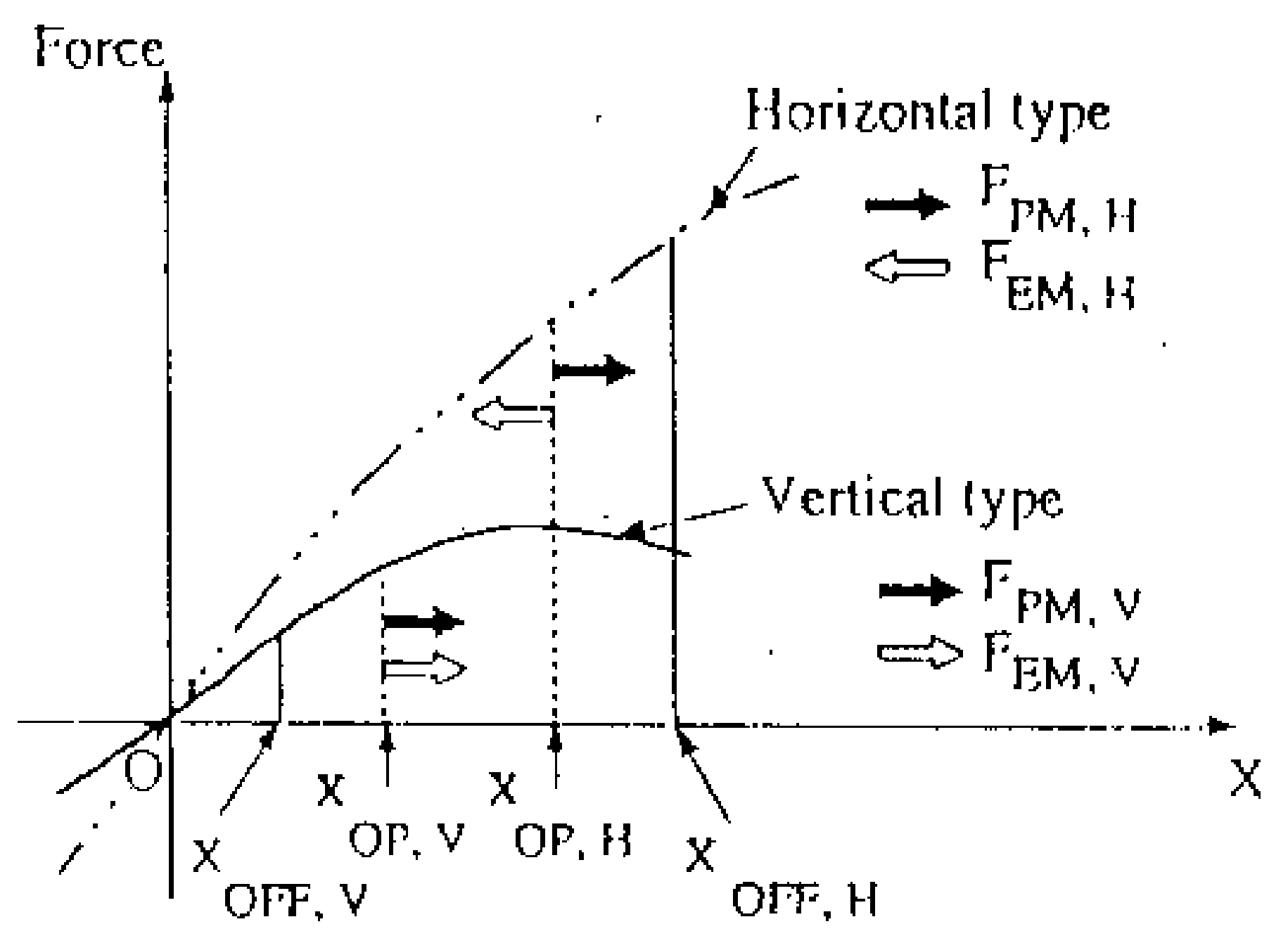

HTG. 12. Off-slate rolor position

\section{OFF-STATE POSITION OF THE ROTOR PM}

Due to the unstable nature of the system along the longitudinal direction, the rotor goes to the extreme of either ofthe two sides and is stopped by the stopper plate. In the vertical-shaft machine the force generated by the electromagnet not only maintains the rotor in the desired position but it also constitutes part of the levitation force. Both the repulsive forces due to permanent magnets and the attractive force due in the electromagnet act in the same direction and, when they join together at a particular position, the rotor is able to levitale. The repulsive forces due to two sets of stator-rotor permancnt magnets at two sides are unable to levitate the rotor. In the off state the rotor goes down to $X_{V}$ as shown in Fig. 12, i.e., on the left of $X_{\text {op }}$, the operating point. It the horizontal-shaft machine the electromagnet has only one function, i.e., to maintain the rotor in a stable position. The force generated by the electromagnet acts in the direction opposite that of the pernianent magnet. In the off-state position the rotor is dragged by the repulsive force and goes to $X_{H}$, i.e., on the right of $X_{\mathrm{OP}}$.

\section{CONCLUSIONS}

In this article we have studied different aspects such as the permanent magnet configuration, disturbance altenuation, field distribution, magnetic losses, deceleration characteristics, and off-state position of the rotor of two types of magnetic bearing systems that are employed for vertical-shaft and horizontal-shaft machines. Although the type of magnetic bearing system used depends on the machine configuration, the specific application requirement, and other criteria, this study can provide first hand knowledge of a few aspects of two different types of repulsive type magnetic bearing systems for the designer.

\footnotetext{
'M. Dussaux, Proceedings of the 2nd International Symposium on Magnclic Bearing. Tokyo, Japan, 1990, pp. 33-38.

${ }^{2}$ J. Delamare, E. Rulliere, and J. P. Yonnel, IEEE Trans. Mngn. 31, 4190 (199.5)

${ }^{3}$ S. C. Mukhopadhyay, T. Ohji, M. Jwahara, S. Yamada, and F. Malsumuta, Proceedings of the IEEE PEDS Conference, Singapore, 26-29 May 1997. P?. $12-18$.

"EMAS-The Finite Elcment Package, ver, 4, ANSOFT Corp., Pillsburgh, 1997.
} 